\title{
Constructal view of scaling laws of river basins
}

\author{
A. Heitor Reis * \\ Physics Department, University of Évora and Évora Geophysics Center, Rua Romão Ramalho 59, 7000-761 Évora, Portugal
}

Received 28 August 2005; received in revised form 7 January 2006; accepted 8 January 2006

Available online 21 February 2006

\begin{abstract}
River basins are examples of naturally organized flow architectures whose scaling properties have been noticed long ago. Based on data of geometric characteristics, Horton [Horton, R.E., 1932. Drainage basin characteristics. EOS Trans. AGU 13, 350-361.], Hack [Hack, J.T., 1957. Studies of longitudinal profiles in Virginia and Maryland. USGS Professional Papers 294-B, Washington DC, pp. 46-97.], and Melton [Melton, M.A, 1958. Correlation structure of morphometric properties of drainage systems and their controlling agents. J. of Geology 66, 35-56.] proposed scaling laws that are considered to describe rather accurately the actual river basins. What we show here is that these scaling laws can be anticipated based on Constructal Theory, which views the pathways by which drainage networks develop in a basin not as the result of chance but as flow architectures that originate naturally as the result of minimization of the overall resistance to flow (Constructal Law).
\end{abstract}

(C) 2006 Elsevier B.V. All rights reserved.

Keywords: River basins; Scaling laws; Constructal theory

\section{Introduction}

Flow architectures are ubiquitous in nature. From the planetary circulations to the smallest scales, we can observe a panoply of motions that exhibit organized flow architectures: general atmospheric circulations, oceanic currents, eddies at the synoptic scale, river drainage basins, dendritic crystals, etc. Fluids circulate in all living structures, which exhibit special flow structures such as lungs, kidneys, arteries, and veins in animals and roots, stems, and leaves in plants.

Rivers are large-scale natural flows that play a major role in the shaping of the Earth's surface. River morphology exhibits similarities that are documented extensively in geophysics treatises. For example, RodríguezIturbe and Rinaldo (1997) gave a broad list of allometric

\footnotetext{
* Tel.: +351 266745372; fax: +351 266745394.

E-mail address: ahr@uevora.pt.
}

and scaling laws involving the geometric parameters of the river channels and of the river basins.

In living structures, heat and mass flow architectures develop with the purpose of dissipating minimum energy, therefore reducing the food or fuel requirement, and making all such systems (animals and "man+ machine" species) more "fit," i.e., better survivors.

Constructal theory views the naturally occurring flow structures (their geometric form) as the end result of a process of area to point flow access optimization with the objective of providing minimal resistance to flow (see Bejan, 2000; Bejan and Lorente, 2004). The Constructal law first put forward by Bejan (1997) stated that "for a finite-size system to persist in time (to live), it must evolve in such a way that it provides easier access to the imposed (global) currents that flow through it."

In the past few decades, extremal hypotheses (e.g. maximum sediment transporting capacity, minimum energy dissipation rate, minimum stream power, minimum 


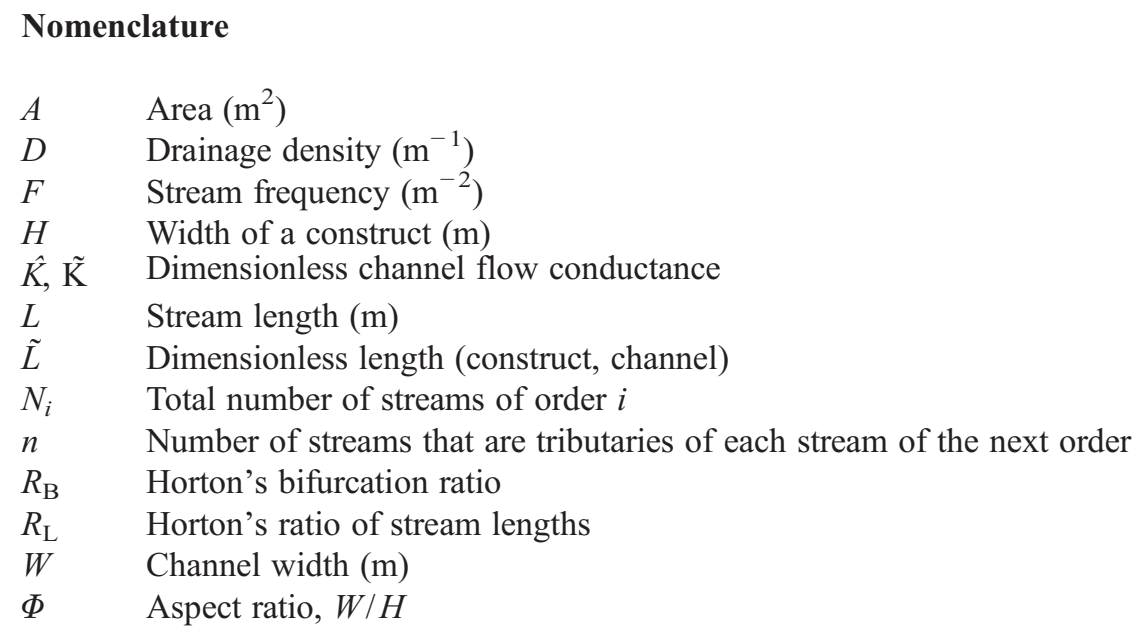

\section{Subscripts}

$i \quad$ Order of a stream

s Relative to stream

T Total

$\omega \quad$ Order of the river basin

$0 \quad$ Relative to the elemental construct

Froude number) have been proposed as basis for deducing specific features of river basin morphology and dynamics (see for example the review by Huang and Nanson, 2000). Fractal geometry has also been used to describe river basin morphology (e.g., Rodríguez-Iturbe and Rinaldo, 1997; Cieplak et al., 1998). Fractals do not account for dynamics, hence are descriptive rather than predictive.

Because the same morphological laws may be deduced in apparently different contexts some authors have considered fluvial networks and basin geometries as canonical examples of equifinality, which is a concept invented by Beven (1993). Equifinality arises when many different parameter sets are equally good at reproducing an output signal. As pointed out by Savenije (2001), although these models may be based on physical relationships they are not unequivocal, and hence are not fit to be used as predictive models.

What is new with Constructal theory is that it unites geometry with dynamics in such a way that geometry is not assumed in advance but is the end result of an optimization procedure. Constructal theory is predictive in the sense that it can anticipate the equilibrium flow architecture that develops under existing constraints. In contrast with fractal geometry, self-similarity needs not to be alleged previously, but appears as a result of the constructal optimization of river networks. Moreover,
Constructal theory shows that the hypotheses of minimum energy dissipation rate and minimum stream power are corollaries of the Constructal law under particular constraints (Reis, 2006).

The aim of this paper is twofold: to show how the scaling laws of river basins may be anticipated based on Constructal theory, and to present this theory to geomorphologists as a useful tool for the study of the

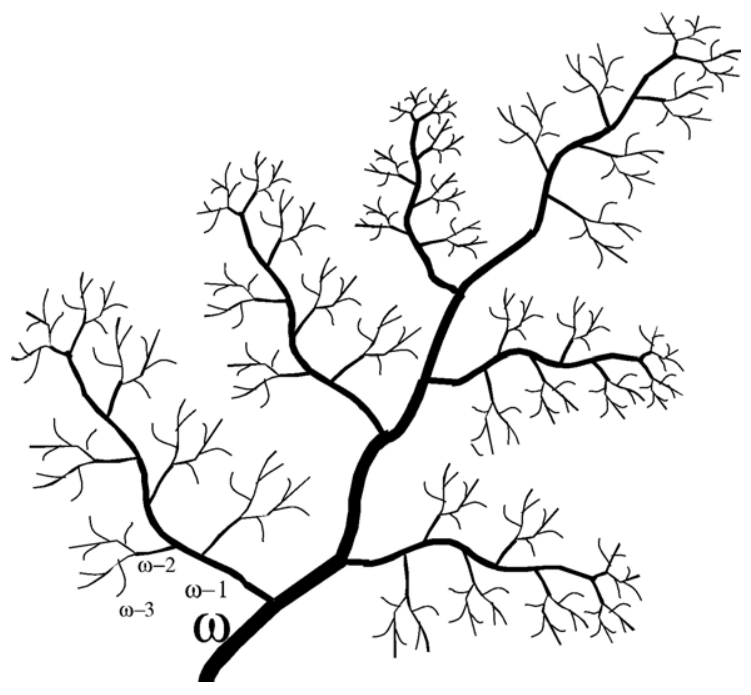

Fig. 1. River network with streams up to order $\omega$. 


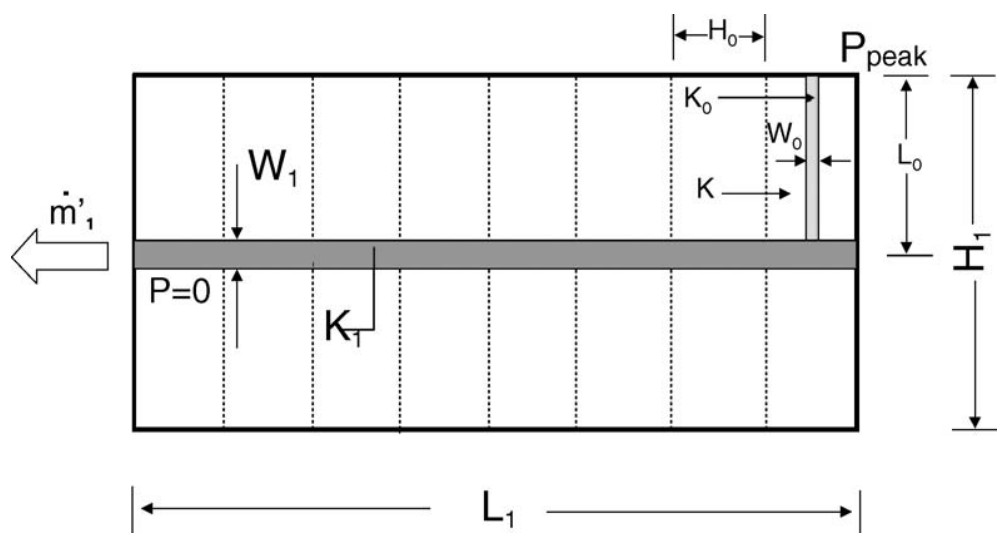

Fig. 2. First construct made of elemental areas, $A_{0}=H_{0} L_{0}$. A new channel of higher flow conductance collects flow from the elemental areas.

structure of natural flows and landforms. This work adds to a constructal model of erosion put forward by Errera and Bejan (1998), which is able to generate dendrite like patterns of low resistance channels by invoking the Constructal law at each optimization step.

\section{Scaling laws of river basins}

River basins are examples of area-to-point flows. Water is collected from an area and conducted through a network of channels of increasing width up to the river mouth. River networks have long been recognized as being self-similar structures over a range of scales. In general, small streams are tributaries of the next bigger stream in such a way that flow architecture develops from the lowest scale to the highest scale, $\omega$ (Fig. 1).

The scaling properties of river networks are summarized in well-known laws. If $L_{i}$ denotes the average of the length of the streams of order $i$, Horton's law of stream lengths states that the ratio

$L_{i} / L_{i-1}=R_{\mathrm{L}}$

is a constant (Horton, 1932; see also Rodríguez-Iturbe and Rinaldo, 1997; Raft et al., 2003). Here, the constant $R_{\mathrm{L}}$ is Horton's ratio of channel lengths. On the other hand, if $N_{i}$ is the number of streams of order $i$, Horton's law of stream numbers asserts constancy of the ratio

$N_{i-1} / N_{i}=R_{\mathrm{B}}$

where $R_{\mathrm{B}}$ is Horton's bifurcation ratio. In river basins, $R_{\mathrm{L}}$ ranges between 1.5 and 3.5 and is typically 2 ; while $R_{\mathrm{B}}$ ranges between 3 and 5 , typically 4 (RodríguezIturbe and Rinaldo, 1997).

The mainstream length $L_{\omega}$ and the area $A_{\omega}$ of a river basin with streams up to order $\omega$ are related through
Hack's law (Hack, 1957; see also Rodríguez-Iturbe and Rinaldo, 1997; Schuller et al., 2001):

$L_{\omega}=\alpha\left(A_{\omega}\right)^{\beta}$

where $\alpha \sim 1.4$ and $\beta \sim 0.568$ are constants.

If we define a drainage density $D_{\omega}=L_{\mathrm{T}} / A$ (where $L_{\mathrm{T}}$ is the total length of streams of all orders and $A$ the total drainage area) and a stream frequency $F_{\mathrm{s}}=N_{\mathrm{s}} / A$ (where $N_{\mathrm{s}}$ is the number of streams of all orders) then Melton's law (Melton, 1958; see also Rodríguez-Iturbe and Rinaldo, 1997; Raft et al., 2003) indicates that the following relation holds:

$F_{\mathrm{s}}=0.694\left(D_{\omega}\right)^{2}$

Other scaling laws relating discharge rate with river width, depth, and slope may be found in the book by Rodríguez-Iturbe and Rinaldo (1997).

\section{River networks as constructal fluid trees}

River basins are examples of area-to-point flow, which is a classical topic of Constructal theory. Darcy flow through a porous medium (soil) predominates at the smallest scale. Channelling develops at a higher scale when it becomes more effective than Darcy flow as a transport mechanism. Bejan has addressed this type of flow and, according to the Constructal law, optimized the channel network that minimizes the overall resistance to flow. A detailed treatment can be found in one of his books (Bejan, 2000, Ch. 5). Here, we summarize the optimized area-to-point flow geometry when the conductance of a channel of width $W$ is given by $K=(1 / 12) W^{2}$, which corresponds to HagenPoiseuille flow between parallel plates. If $H_{i}$ and $L_{i}$ represent the dimensions of the area $A_{i}=H_{i} \times L_{i}$ allocated 
Table 1

The optimized geometry of area-to-point flow (channels with HagenPoiseuille flow; Bejan, 2000) $\left(\hat{K}=K / A_{0} ; \quad\left(\tilde{H}_{i}, \tilde{L}_{i}\right)=\left(H_{i}, L_{i}\right) /\left(A_{0}\right)^{1 / 2}\right.$; $\left.\Phi_{i}=W_{i} / H_{i}\right)$

\begin{tabular}{|c|c|c|c|}
\hline & $\tilde{H}_{i}$ & $\tilde{L}_{i}$ & $n_{i}$ \\
\hline 0 & $\frac{2^{5 / 6} 3^{1 / 6} \hat{K}^{1 / 6}}{\Phi_{0}^{1 / 2}}$ & $\frac{\Phi_{0}^{1 / 2}}{2^{5 / 6} 3^{1 / 6} \hat{K}^{1 / 6}}$ & - \\
\hline 1 & $\frac{2^{1 / 6} \Phi_{0}^{1 / 2}}{3^{1 / 6} \hat{K}^{1 / 6}}$ & $\frac{\Phi_{1}^{3 / 2}}{2^{3 / 2} \hat{K}^{1 / 2}}$ & $\frac{\Phi_{1}^{3 / 2} \Phi_{0}^{1 / 2}}{2^{4 / 3} 3^{1 / 6} \hat{K}^{2 / 3}}$ \\
\hline 2 & $\frac{\Phi_{1}^{3 / 2}}{2^{1 / 2} \hat{K}^{1 / 2}}$ & $\frac{3^{1 / 6}\left(\Phi_{2} \Phi_{1}\right)^{3 / 2}}{2^{5 / 3} \Phi_{0}^{1 / 2} \hat{K}^{5 / 6}}$ & $\frac{3^{1 / 3}\left(\Phi_{2} \Phi\right)^{3 / 2}}{2^{5 / 6} \Phi_{0} \hat{K}^{2 / 3}}$ \\
\hline 3 & $\frac{3^{1 / 6}\left(\Phi_{2} \Phi_{1}\right)^{3 / 2}}{2^{2 / 3} \Phi_{0}^{1 / 2} \hat{K}^{5 / 6}}$ & $\frac{3^{1 / 3}\left(\Phi_{3} \Phi_{2} \Phi_{1}\right)^{3 / 2}}{2^{4 / 3} \Phi_{0} \hat{K}^{7 / 6}}$ & $\frac{2^{1 / 6} 3^{1 / 3}\left(\Phi_{3} \Phi_{2}\right)^{3 / 2}}{\Phi_{0} \hat{K}^{2 / 3}}$ \\
\hline 4 & $\frac{3^{2 / 3}\left(\Phi_{3} \Phi_{2} \Phi_{1}\right)^{3 / 2}}{2^{1 / 3} \Phi_{0} \hat{K}^{7 / 6}}$ & $\frac{3^{1 / 2}\left(\Phi_{4} \Phi_{3} \Phi_{2} \Phi_{1}\right)^{3 / 2}}{2^{1 / 2} \Phi_{0}^{3 / 2} \hat{K}^{9 / 6}}$ & $\frac{2^{7 / 6} 3^{2 / 3}\left(\Phi_{4} \Phi_{3}\right)^{3 / 2}}{\Phi_{0} \hat{K}^{2 / 3}}$ \\
\hline
\end{tabular}

to each stream of order $i$, the peak pressure $P_{\text {peak, } 1}$ at the farthest corner of the first construct (see Fig. 2) is given by (Bejan, 2000)

$\frac{P_{\text {peak }, 1}}{\dot{m}_{1}^{\prime} v / K}=\frac{1}{4 \widetilde{K}_{0} \Phi_{0}} \frac{H_{1}}{L_{1}}+\frac{1}{2 \widetilde{K}_{1} \Phi_{1}} \frac{L_{1}}{H_{1}}$

where $\dot{m}_{1}^{\prime}$ represents total mass flow rate, $v$ is viscosity of water, $\tilde{K}_{i}=K_{i} / K$, and $\Phi_{i}=W_{i} / H_{i}$. Minimizing the flow resistance over the first construct is equivalent to minimize the peak pressure, $P_{\text {peak }, 1}$, in Eq. (5). Each new construct $A_{i}$ contains $n_{i}$ constructs of area $A_{i-1}$, the flow of which is collected by a new high conductance channel. The maximum pressure difference sustained by $A_{i}$ is equal to the sum of the pressure difference across the already optimized constituent $A_{i-1}$ that occupies the farthest corner of $A_{i}$, and the pressure drop along the central channel of $A_{i}$ (Bejan, 2000):

$P_{\text {peak }, i}=P_{\text {peak }, i-1}+\dot{m}_{i}^{\prime} v \frac{L_{i}}{2 K_{i} W_{i}}$

With $n_{i}$ representing the number of streams of order $i-1$ that are tributaries of each stream of order $i$, the

Table 2

The jointly optimized network parameters (minimization of the overall resistance to flow and optimization of void stream area allocation)

\begin{tabular}{lll}
\hline & $\tilde{L}_{i}$ & $\mathrm{n}_{i}$ \\
\hline 0 & $0.47\left(\Phi_{0} \hat{K}^{-1 / 3}\right)^{1 / 2}$ & - \\
1 & $0.36\left(\Phi_{0} \hat{K}^{1 / 3}\right)^{3 / 2}$ & $0.33\left(\Phi_{0} \hat{K}^{1 / 3}\right)^{2}$ \\
2 & $0.30\left(\Phi_{0} \hat{K}^{1 / 3}\right)^{5 / 2}$ & $0.81\left(\Phi_{0} \hat{K}^{1 / 3}\right)^{2}$ \\
3 & $0.31\left(\Phi_{0} \hat{K}^{1 / 3}\right)^{7 / 2}$ & $0.88\left(\Phi_{0} \hat{K}^{1 / 3}\right)^{2}$ \\
4 & $0.41\left(\Phi_{0} \hat{K}^{-1 / 3}\right)^{9 / 2}$ & $2.00\left(\Phi_{0} \hat{K}^{1 / 3}\right)^{2}$ \\
\hline
\end{tabular}

Table 3

Constructal Horton ratios of stream lengths, $R_{\mathrm{L}}$

\begin{tabular}{llll}
\hline$\tilde{L}_{1} / \tilde{L}_{0}$ & $\tilde{L}_{2} / \tilde{L}_{1}$ & $\tilde{L}_{3} / \tilde{L}_{2}$ & $\tilde{L}_{4} / \tilde{L}_{3}$ \\
\hline $0.76 \Phi_{0} \hat{K}^{-\frac{1}{3}}$ & $0.85 \Phi_{0} \hat{K}^{-\frac{1}{3}}$ & $1.04 \Phi_{0} \hat{K}^{-\frac{1}{3}}$ & $1.33 \Phi_{0} \hat{K}^{-\frac{1}{3}}$ \\
\hline
\end{tabular}

optimized values of stream channels up to order 4 are shown in Table 1.

A second kind of constructal optimization is performed with respect to the optimal distribution of the total void volume corresponding to the channels. The optimal allocation of channel volume is such that it minimizes the global void volume under both constant basin area and flow resistance (see Bejan and Lorente, 2004). The void-allocation (channel) optimization provides the following additional relationships (Bejan, 2000, pp. 91-94):

$$
\begin{aligned}
& \Phi_{1}=\Phi_{0} ; \quad \Phi_{2}=(6 / 7) \Phi_{0} ; \\
& \Phi_{3}=(60 / 77) \Phi_{0} ; \quad \Phi_{4}=(8 / 11) \Phi_{0}
\end{aligned}
$$

With Eq. (7), $L_{i}$ and $n_{i}$ may be rewritten in the forms shown in Table 2 . Both $\tilde{L}_{i}$ and $n_{i}$ depend uniquely on $\Phi_{0} \hat{K}^{-1 / 3}$ which, in turn, is the product of two terms: (i) $\Phi_{0}$ that represents the ratio of the area of the smallest (first order) channel to the area of the porous layer that feeds it and (ii) the dimensionless conductance $\hat{K}$ raised to the power $(-1 / 3)$.

As none of these parameters depend upon the particular geometry of the layer, we conclude that despite the relationships of Tables 1 and 2 being derived from constructs of regular geometry as that of Fig. 2, the relationships in Table 2 are applicable to any hierarchical stream network irrespective to its particular geometry. Channel hierarchy is understood in the Hortonian sense, i.e., all streams of order $i$ are tributaries of streams of order $i+1$.

River basins are examples of area-to-point flows that approach the Hortonian hierarchy; therefore, the constructal rules defined in Table 2 for stream networks up to order 4 must hold, at least approximately. For example, with the use of Table 2, the ratios of the lengths of consecutive streams are given in Table 3 . We see that the ratio of the characteristic lengths of streams of consecutive order $\tilde{L}_{i-1} / \tilde{L}_{i} \sim \Phi_{0} \hat{K}^{-1 / 3}$ is practically constant as required by Horton's law of stream lengths (Eq. (1)).

To check if the constructal relations in Table 2 match Horton's law of stream numbers (Eq. (2)), we calculate the number $N_{i}$ of streams up to order $i$, which is given by

$N_{i}=n_{i} \times n_{i-1} \times n_{i-2} \times \cdots \times n_{1}$ 
Table 4

Dimensionless area of constructal river basins up to order 4

\begin{tabular}{lllll}
\hline$\tilde{A}_{0}$ & $\tilde{A}_{1}$ & $\tilde{A}_{2}$ & $\tilde{A}_{3}$ & $\tilde{A}_{4}$ \\
\hline 1 & $0.33\left(\Phi_{0} \hat{K}^{-1 / 3}\right)^{2}$ & $0.21\left(\Phi_{0} \hat{K}^{-1 / 3}\right)^{4}$ & $0.19\left(\Phi_{0} \hat{K}^{-1 / 3}\right)^{6}$ & $0.37\left(\Phi_{0} \hat{K}^{-1 / 3}\right)^{8}$ \\
\hline
\end{tabular}

where $n_{j}$ is the number of streams of order $j$ that are tributaries of each stream of order $j+1$. Taking into account Eq. (8), the ratio of the number of streams up to order $i$ to the number of streams up to order $i-1$ is given by

$N_{i} / N_{i-1}=n_{i}$

The ratios $n_{i}$ are shown in Table 2. We conclude that these ratios are almost of the same order, i.e., $N_{i}$ / $N_{i+1} \sim\left(\Phi_{0} \hat{K}^{-1 / 3}\right)^{2}$; therefore matching Horton's law of stream numbers, closely. Recalling that the ratio of stream lengths is $\tilde{L}_{i+1} / \tilde{L}_{i} \sim \Phi_{0} \hat{K}^{-1 / 3}$, we conclude that

$N_{i} / N_{i+1} \sim\left(\widetilde{L}_{i+1} / \widetilde{L}_{i}\right)^{2}$

i.e., the ratio of stream numbers is of the order of the square of the ratio of stream lengths. As stated in the Introduction, in real river basins $L_{i} / L_{i-1}=R_{\mathrm{L}}$ ranges between 1.5 and 3.5 , and is typically 2 , while $n_{i-1} /$ $n_{i}=R_{\mathrm{B}}$ ranges between 3 and 5, typically 4 (RodríguezIturbe and Rinaldo, 1997; Raft et al., 2003), i.e., the constructal rule evinced by Eq. (10) is closely verified for the real river basins.

Next we are going to show that Hack's law (Eq. (3)) also follows from the constructal relationships of Tables 1 and 2. Noting that $A_{i}=H_{i} L_{i}$ and using Table 1 and Eq. (7), we obtain the subbasin areas shown in Table 4. The constructal relationships between mainstream length $L_{\omega}$ and the area $A_{\omega}$ of a river basin with streams up to order $\omega$ are determined by using Table 4 together with Table 2 and are shown in Table 5. Gray (1961) found $\beta \sim 0.568$ while Muller (1973) reported that $\beta \sim 0.6$ for river basins $<8000 \mathrm{mi}^{2}(1 \mathrm{mile}=1609.3 \mathrm{~m}), \beta \sim 0.5$ for basins between 8000 and $100,000 \mathrm{mi}^{2}$, and $\beta \sim 0.47$ for basins $>100,000 \mathrm{mi}^{2}$ (see also Schuller et al., 2001).

The constructal rule for the exponent $\beta$ is the following:

$\beta_{\omega}=\frac{2 \omega+1}{4 \omega}$

We see from Eq. (11) that as the order of the river basin increases, $\beta$ approaches 0.5 in good agreement with Muller's findings for actual river basins.

Table 5

Constructal Hack's exponent $\beta$ for river basins up to order 4

\begin{tabular}{llll}
\hline$\tilde{L}_{1} \sim A_{1}^{0.75}$ & $\tilde{L}_{2} \sim A_{2}^{0.62}$ & $\tilde{L}_{1} \sim A_{3}^{0.58}$ & $\tilde{L}_{4} \sim A_{4}^{0.56}$ \\
\hline$\beta=0.75$ & $\beta=0.63$ & $\beta=0.58$ & $\beta=0.56$ \\
\hline
\end{tabular}

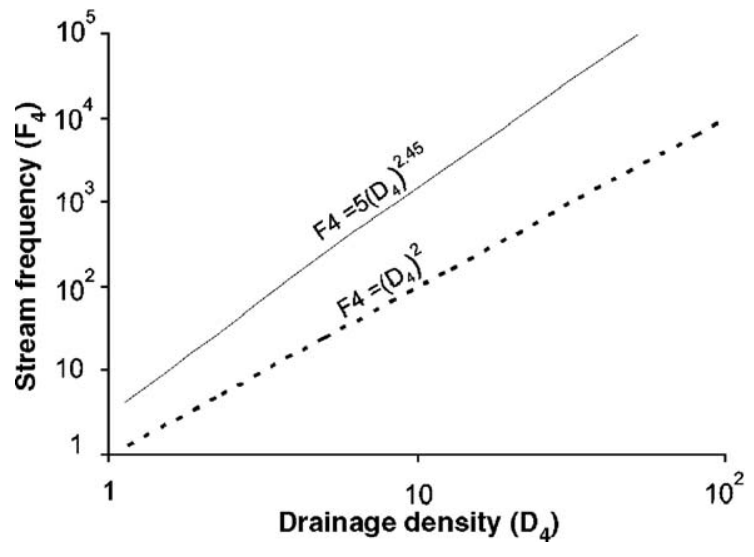

Fig. 3. For a river basin of order 4 , the constructal relationships indicate that steam frequency is proportional to drainage density raised to a power of 2.45, which is close to 2 (Melton's law).

In order to check Melton's law, first we calculate the drainage density $D_{\omega}$ as

$D_{\omega}=\sum_{i=1}^{\omega} n_{i} \widetilde{L}_{i} / \widetilde{H}_{\omega} \widetilde{L}_{\omega}$

and the stream frequency as

$F_{\omega}=\sum_{i=1}^{\omega} N_{i} / \widetilde{H}_{\omega} \widetilde{L}_{\omega}$

By using Tables 1 and 2 and with the help of Eq. (8) we obtain:

$$
\begin{aligned}
D_{4}= & 0.18\left(\Phi_{0} \hat{K}^{-1 / 3}\right)+0.14\left(\Phi_{0} \hat{K}^{-1 / 3}\right)^{-0.5} \\
& +0.35\left(\Phi_{0} \hat{K}^{-1 / 3}\right)^{-1.5}+0.44\left(\Phi_{0} \hat{K}^{-1 / 3}\right)^{-2.5}
\end{aligned}
$$

and

$$
\begin{aligned}
F_{4}= & 1+0.38\left(\Phi_{0} \hat{K}^{-1 / 3}\right)^{-2}+1.16\left(\Phi_{0} \hat{K}^{-1 / 3}\right)^{-4} \\
& +1.42\left(\Phi_{0} \hat{K}^{-1 / 3}\right)^{-6}
\end{aligned}
$$

We note that the drainage density of a stream of order 0 is $\left(L_{0} / H_{0}\right)^{1 / 2}$, while the stream frequency is 1 , which is the lowest limit.

The variation of $F_{4}$ with $D_{4}$ is shown in Fig. 3. We see that the constructal relations in Eqs. (14) and (15) follow Melton's law quite approximately in the range $1<D_{4}<10^{2}$, i.e., $F_{4}$ is proportional to $D_{4}$ raised to the power 2.45 .

The scaling laws of river basins evince the organized flow architectures that result from the underlying struggle for better performance, by reducing the overall 
resistance in order to drain water from the basins the fastest (Constructal law) and the best uniformly distributed all over the basin area.

\section{Conclusions}

Despite only basins with streams up to order 4 having been considered in this paper, we believe that the conclusions do extend to higher order river basins.

The scaling laws of geometric features of river basins can be anticipated based on Constructal theory, which views the pathways by which drainage networks develop in a basin not as the result of chance but as flow architectures that originate naturally as the result of minimization of the overall resistance to flow (Constructal law).

The ratio of constructal lengths of consecutive streams matches Horton's law for the same ratio, while the same occurs with the number of consecutive streams that match Horton's law of ratios of consecutive stream numbers.

Hack's law is also correctly anticipated by the constructal relations that provide Hack's exponent accurately.

Melton's law is anticipated approximately by the constructal relationships that indicate 2.45 instead of 2 for Melton's exponent. However, the difficulty to calculate correctly the drainage density and the stream frequency from field data indicates that some uncertainty must be assigned to Melton's exponent.

These results add to many other examples of complex flows, either from engineering (e.g., Bejan, 2000; Bejan et al., 2004) or from animate structures (e.g. Bejan, 2000; Reis et al., 2004), in which the Constructal law proved to play a fundamental role.

\section{References}

Bejan, A., 1997. Advanced Engineering Thermodynamics, 2nd Ed. Wiley, New York. Ch. 13.
Bejan, A., 2000. Shape and Structure, from Engineering to Nature Cambridge University Press, Cambridge, UK.

Bejan, A., Lorente, S., 2004. The Constructal law and the thermodynamics of flow systems with configuration. Int. J. Heat Mass Transfer 47, 3203-3214.

Bejan, A., Dincer, I., Lorente, S., Miguel, A.F., Reis, A.H., 2004. Porous and Complex Flow Structures in Modern Technologies. Springer-Verlag, New York.

Beven, K., 1993. Prophesy, reality and uncertainty in distributed hydrological modelling. Adv. Water Resour. 16, 41-51.

Cieplak, M., Giacometti, A., Maritan, A., Rinaldo, A., RodriguezIturbe, I., Banavar, J.R., 1998. Models of fractal river basins. J. Stat. Phys. 91, 1-15.

Errera, M.R., Bejan, A., 1998. Deterministic tree networks for river drainage basins. Fractals 6, 245-261.

Gray, D.M., 1961. Interrelationship of watershed characteristics. J. Geophys. Res. 66, 1215-1223.

Hack, J.T., 1957. Studies of longitudinal profiles in Virginia and Maryland. USGS Professional Papers 294-B, Washington DC, pp. $46-97$.

Horton, R.E., 1932. Drainage basin characteristics. EOS Trans. AGU 13, 350-361.

Huang, H.Q., Nanson, G.C., 2000. Hydraulic geometry and maximum flow efficiency as products of the principle of least action. Earth Surf. Process. Landf. 25, 1-16.

Melton, M.A., 1958. Correlation structure of morphometric properties of drainage systems and their controlling agents. J. Geol. 66, $35-56$.

Muller, J.E., 1973. Re-evaluation of the relationship of master streams and drainage basins: reply. Geol. Soc. Amer. Bull. 84, 3127-3130.

Raft, D.A., Smith, J.L., Trlica, M.J., 2003. Statistical descriptions of channel networks and their shapes on non-vegetated hillslopes in Kemmerer, Wyoming. Hydrol. Process. 17, 1887-1897.

Reis, A.H., 2006. Constructal Theory: from Engineering to Physics, or How Flow Systems Develop Shape and Structure. (To appear in Applied Mechanics Reviews).

Reis, A.H., Miguel, A.F., Aydin, M., 2004. Constructal theory of flow architectures of the lungs. Med. Phys. 31 (5), 1135-1140.

Rodríguez-Iturbe, I., Rinaldo, A., 1997. Fractal River Basins. Cambridge University Press, New York.

Savenije, H.H.G., 2001. Equifinality, a blessing in disguise? Hydrol. Process. 15, 2835-2838.

Schuller, D.J., Rao, A.R., Jeong, G.D., 2001. Fractal characteristics of dense stream networks. J. Hydrol. 243, 1-16. 